ISSN = 1980-993X - doi:10.4136/1980-993X
www.agro.unitau.br/ambi-agua
E-mail: ambi-agua@agro.unitau.br
Tel.: (12) 3625-4116

\title{
Emprego de técnicas digitais para a concepção da base cartográfica da bacia hidrográfica do Córrego Cabuçu de Baixo, São Paulo, SP, Brasil
} (doi:10.4136/ambi-agua.44)

\author{
Rodrigo Affonso de Albuquerque Nóbrega ${ }^{1}$; Mario Thadeu Leme de Barros ${ }^{2}$; \\ José Alberto Quintanilha ${ }^{1}$ \\ Escola Politécnica da Universidade de São Paulo - ${ }^{1}$ Lab. de Geoprocessamento do Depto. de Eng. de \\ Transportes e ${ }^{2}$ Departamento de Engenharia Hidráulica e Sanitária \\ E-mail: rodrigo.nobrega@poli.usp.br; mtbarros@usp.br; jaquinta@usp.br
}

\section{RESUMO}

O emprego de bases cartográficas confiáveis como material de apoio a projetos de planejamento e gestão espacial é de caráter primordial ao seu sucesso. Todavia, a escassez e a desatualização desse material tem levado à adoção de metodologias alternativas, na busca de soluções mais rápidas e menos onerosas para elaboração dessas informações, sem que haja o comprometimento da qualidade. Nesse contexto, o presente trabalho mostra a viabilidade da construção de uma base cartográfica voltada para as aplicações em hidrologia, mais especificamente, como base para um Sistema de Suporte à Decisão para Gerenciamento de Bacia Urbana - SSDURB. A metodologia aqui apresentada reúne técnicas de extração manual das feições do terreno, bem como técnicas automáticas de fotogrametria. Como produtos, foram obtidas ortofotos e cartas altimétricas, com eqüidistância de 5 metros para as regiões montanhosas com cobertura florestal e de 1 metro para as demais áreas, priorizando as áreas de várzea para análise de pontos de alagamento. Análises finais mostram a viabilidade do emprego da metodologia proposta e a alta qualidade dos produtos.

Palavras-chave: modelo digital de terreno; ortofoto; hidrologia urbana; gestão de recursos hídricos; água urbana.

\section{Application of digital techniques to generate a cartographic database of Córrego do Cabuçu de Baixo basin, São Paulo, SP, Brazil}

\section{ABSTRACT}

The use of appropriate cartography database is extremely important to support projects of planning and land management. However, the absence of maps, or the amount of obsolete maps, has been leading to the adoption of alternative methodologies aiming to faster and less onerous solutions for the development of cartography databases, without compromising quality. Regarding this problem, the present paper reports on the viability of constructing a cartographic database designed for applications in hydrology, more specifically, as a base for a Decision Support System for Urban Basin Management - DSSURM. The methodology combines techniques of manual terrain features extraction, as well as automatic techniques of photogrammetry. Digital orthophotos and contour maps were generated. The coarser 5 meters interval was used for the mountainous regions and forest, and the finer 1 meter interval for other regions, floodplains were prioritized for mapping flooding areas. The final analyses show the viability of the methodology as well as the high quality of the cartographic products.

Keywords: digital terrain modeling; orthophoto; urban hydrology; hydro resources management; urban water. 


\section{INTRODUÇÃO}

Os problemas relativos à água no meio urbano são hoje extremamente preocupantes e envolvem questões econômicas, sociais e ambientais complexas, principalmente em grandes cidades, nas chamadas megacidades, como São Paulo, Rio de Janeiro, etc. O equacionamento e a solução desses problemas envolvem profissionais de diferentes áreas do conhecimento e necessitam de muito planejamento, muito estudo, para que as soluções propostas sejam de fato eficientes.

A inclusão de questões relativas à água urbana nos Planos de Bacia Hidrográfica, instrumento base do Sistema de Gerenciamento de Recursos Hídricos no Brasil e nos Planos Diretores das cidades é fundamental para que se possa avançar em soluções. Os programas e projetos de água urbana estão diretamente relacionados à melhoria do meio e do padrão de vida do homem urbano. Nesse sentido, é fundamental o desenvolvimento de ferramentas de planejamento e gestão municipal que possa enfocar, principalmente, a pequena bacia hidrográfica urbana. A urbanização e a gestão municipal praticamente desfiguraram as pequenas bacias hidrográficas e, infelizmente, muitos dos problemas existentes nas áreas urbanas advêm da falta de planejamento e de gestão feitas com base na bacia hidrográfica.

A Escola Politécnica da Universidade de São Paulo (EPUSP), via seu Departamento de Engenharia Hidráulica e Sanitária (PHD), propôs ao Fundo Setorial de Recursos Hídricos (CT-HIDRO) dois projetos voltados às questões da água urbana e ambos estudaram os problemas sob a ótica da pequena bacia urbana. Um desses projetos trata do desenvolvimento de uma ferramenta de planejamento e de gestão urbana, chamada de Sistema de Suporte à Decisão para Gerenciamento de Bacia Urbana - SSDURB (Barros, 2004a e 2004b). O outro projeto trata de ações mais específicas, chamado Plano de Bacia Urbana (Barros, 2005). Esse sistema de suporte à decisão (SSD) permite a um usuário processar diferentes tipos de modelos matemáticos de quantidade e qualidade da água para simular diferentes cenários de ocupação e uso do solo. Acoplado a esse SSD foi desenvolvido um banco de dados detalhado, com informações dos mais variados tipos, todas relacionadas com a água urbana.

O SSDURB foi montado para a bacia do córrego Cabuçu de Baixo em São Paulo, região que caracteriza muito bem os problemas de água que a cidade enfrenta. A disponibilidade de informações confiáveis é a base de sustentação de um SSD. Nesse sentido, o projeto se preocupou em montar um banco de dados para servir de referência para outras áreas urbanas.

Segundo Choi et al. (2005), avanços recentes em tecnologia da informação, incluindo hardware, software e internet, têm fornecido soluções para diferentes aspectos da modelagem hidrológica. Atualmente, velocidade e capacidade de armazenamento dos computadores, redes e software de análise espacial permitem a simulação hidrológica distribuída, tornando possível a consideração da variação espacial. Sistemas de informações geográficas (SIG) tiveram um forte impacto na modelagem hidrológica e no desenvolvimento de modelos (Xu et al., 2001). Ferramentas SIG são comumente usadas em sistemas de suporte à decisão para preparação de dados, operação e modelagem de sistemas hidrológicos e tornaram-se ferramentas essenciais para o desenvolvimento de sistemas de suporte à decisão espacial para o gerenciamento de bacias. (Tayler et al., 1999; Lohani et al., 2002; Watson et al., 2002; Wilson et al., 2000). Em particular, Choi et al. (2005) descrevem um SSD desenvolvido em ambiente web-GIS para entrada de dados, apresentação de mapas e delineamento dos contornos de bacias online. Zerger e Wealands (2004) descrevem o desenvolvimento de um SDS que integra resultados de modelos hidrodinâmicos, SIG e sistemas gerenciadores de banco de dados. Dymond et al. (2004) usam um SSD em ambiente web-GIS para integrar modelos hidrológicos e econômicos com diferentes resoluções espaciais e temporais. 
A base cartográfica e altimétrica para aplicação de modelos hidrológicos, hidráulicos e de qualidade da água em pequenas áreas urbanas é uma informação essencial. Superfícies tridimensionais representam dados de elevação. Essas superfícies podem ser geradas usando diferentes abordagens, dependendo do software ou da representação de dados, vetorial ou matricial, utilizada (Rainis, 2004). Uma revisão de diferentes tipos de algoritmos pode ser encontrada em Skidmore (1989), Dunn e Hickey (1998) e Burrough e McDonnell (1998).

As imagens de satélites de sensoriamento remoto na região óptica (visível e infravermelho próximo) do espectro eletromagnético não apresentavam potencial de aplicação para áreas urbanas com os sensores de média resolução ( $30 \mathrm{~m})$. No entanto, com o advento dos sensores imageadores de maior resolução espacial, como o IKONOS (1m), QuickBird (0,6m), HRG/SPOT-5 (2,5m) e, mais recentemente, o HRC/CBERS-2b (2,7m), abriram-se novas perspectivas para o uso dessas imagens para análises urbanas.

Distorções geométricas causadas pela forma de obtenção das imagens (visadas fora do nadir), instabilidade da plataforma e rotação e curvatura da Terra são comuns em imagens captadas por satélites de sensoriamento remoto.

Áreas urbanas com edificações de diferentes alturas introduzem distorções adicionais (objetos pequenos sobre as edificações, muros e divisas entre as edificações, não são completamente ortorretificados, devido à falta de exatidão do modelo digital de terreno (MDT) (Zhou et al., 2005).

A ortorretificação é uma das maneiras de se reduzir essas distorções. Entende-se por ortofoto uma imagem que sofreu um processo de ortorretificação, o qual é responsável pela correção causada pelo efeito do terreno, pela orientação da aeronave e pelo efeito de projeção cônica natural do sistema de lentes da câmara (Church, 1976, apud McGlone, 2004). Para corrigir as elevações, é necessário o uso de modelos digitais de terreno (MDT), obtidos a partir de técnicas de fotogrametria digital aplicadas às estereo-imagens de alta resolução espacial, semelhantes àquelas usadas em fotografias aéreas (Gooch and Chandler, 1998; Chandler, 1999).

Existe uma grande variedade de formas para obtenção de um modelo digital de terreno (MDT). Zeilhofer (2001) destaca o levantamento topográfico em campo, restituição fotogramétrica e a interferometria a partir de dados de sistemas imageadores de radar. Para Jacobsen (2001), a correlação automática de imagens e o imageamento por laser (Light Detector And Ranging - LiDAR) estão entre as técnicas de modelagem digital mais empregadas na atualidade. Embora haja uma forte tendência ao emprego dessas técnicas, por utilizarem tecnologia de ponta e possibilitarem o levantamento rápido e preciso do terreno, o custo dessa atualização tecnológica as tornam inacessíveis para grande parte dos projetos atuais.

Como alternativas mais tradicionais, existe o emprego de cartas topográficas digitalizadas ou o uso de fotografias aéreas (ou imagens de satélites). O emprego de cartas topográficas pode ser uma boa solução, poupando o trabalho de levantamento em campo (Zeilhofer, 2001). Todavia, a qualidade do MDT estará diretamente ligada à qualidade da carta topográfica de origem. Embora, em geral, as cartas topográficas sejam produzidas segundo critérios que garantam a precisão, a atualização das bases cartográficas no Brasil não é feita regularmente, elevando o risco de se trabalhar com dados incorretos. Eficientes e precisas, a adoção de fotografias aéreas para restituição da superfície topográfica acaba elevando os custos do projeto, uma vez que esse processo é manual e depende da habilidade e da acuidade visual do operador.

No contexto da cartografia digital, pela facilidade de seu emprego em programas de geoprocessamento e pelos benefícios oferecidos, as ortofotos vêm ganhando destaque, segundo Queiroz Filho (1993). O processo de ortorretificação foi proposto por Russel Bean, 
do serviço geológico norte-americano - USGS, em meados de 1955, utilizando na época recursos ópticos/mecânicos e a habilidade do operador na compensação da variação do relevo para produzir as ortofotos. Atualmente, a ortorretificação utiliza basicamente rotinas de processamento digital de imagem e a influência do relevo é compensada automaticamente pelo uso do modelo digital do terreno. Uma revisão detalhada sobre o processo de ortorretificação pode ser encontrada no capítulo 13 "Photogrammetric products" de McGlone (2004). Nesse capítulo são discutidos vários produtos cartográficos digitais, dados gerados por sistemas de informações geográficas e a visualização 3D.

Wechsler (2007) examinou a natureza e a importância do gerenciamento de incertezas nos modelos digitais de terreno (MDT) em hidrologia. Essa revisão discute o que o autor chama de "áreas fundamentais" da modelagem digital de terrenos e que afetam o uso de MDT em aplicações hidrológicas. Essas áreas fundamentais incluem: a) erros no MDT; b) parâmetros topográficos freqüentemente derivados dos MDT e algoritmos associados à geração desses MDT; c) a influência da escala do MDT imposta pela resolução da malha utilizada; d) a interpolação no MDT; e) as modificações inseridas no terreno para gerar superfícies MDT hidrologicamente viáveis.

Outro aspecto relevante na escolha do método de MDT envolve a análise da forma com que as informações do terreno são representadas. Os modelos clássicos são a malha regular (GRID) e a malha de triângulos irregulares (TIN). O modelo GRID, por exemplo, apresenta grande facilidade de implementação e execução, todavia não permite representar detalhes com dimensões inferiores ao espaçamento da malha. A adoção de uma malha densa pode comprometer o desempenho do sistema e gerar redundância em regiões planas ou de declividade constante. O TIN, embora necessite de aplicativos mais sofisticados para execução, permite a representação do relevo em detalhes, pois permite adaptar a dimensão dos triângulos às irregularidades naturais e artificiais do terreno. Maiores detalhes podem ser vistos em McGlone (2004) e Maune (2007).

Na prática, o levantamento de dados na bacia do Cabuçu de Baixo evidenciou um problema crônico, infelizmente, comum em projetos de recursos hídricos: a falta de informações cartográficas confiáveis e atualizadas. O objetivo deste artigo é apresentar uma metodologia alternativa desenvolvida para a geração da superfície topográfica e o seu emprego na produção de ortofotos para subsidiar a coleta de informações planimétricas, com qualidade compatível com a modelação matemática do SSDURB.

Dadas às restrições de recursos e de tempo, a técnica de mapeamento aqui apresentada demonstrou ser muito adequada às análises feitas pelo SSDURB. A base cartográfica gerada, constituída por cartas altimétricas e ortofotos digitais, possibilitou que o projeto fosse subsidiado por informações precisas, tendo em vista os objetivos do SSD. Além disso, a altimetria permitiu a elaboração de pranchas tridimensionais que em muito contribuíram para análise espacial de propostas de intervenção na bacia, executadas posteriormente (Barros, 2005).

\section{MATERIAIS E MÉTODOS}

\section{1. Área de Estudo}

A área de estudo em questão, corresponde à bacia do córrego Cabuçu de Baixo, localizada no extremo norte do município de São Paulo-SP, compreendida entre as latitudes $23^{\circ} 24^{\prime} 30^{\prime \prime}$ S e $23^{\circ} 30^{\prime} 30^{\prime \prime}$ S e as longitudes $46^{\circ} 37^{\prime} 30^{\prime \prime}$ W e $46^{\circ} 43^{\prime \prime} 50^{\prime \prime}$ W, em uma área de aproximadamente $42 \mathrm{Km}^{2}$ e perímetro de aproximado de $45 \mathrm{~km}$ (Figura 1). A Bacia do Cabuçu de Baixo é formada à montante pelas sub-bacias dos Córregos do Bananal, Guaraú, 
Itaguaçu e Bispo e à jusante pelo Córrego do Cabuçu de Baixo. Ao Norte, sua extensão abrange parte da Serra da Cantareira, limitada pelas divisas entre os municípios de São Paulo, Mairiporã e Caieiras. Ao sul, a bacia sofre um estreitamento até sua jusante no Rio Tietê. Sua extensão territorial abrange principalmente os bairros da Freguesia do Ó, Vila Nova Cachoeirinha, Vila Brasilândia, Horto Florestal e Parada de Taipas. Maiores detalhes podem ser vistos em Barros (2004b).

Devido à abrangência da bacia, a cobertura do solo pode ser dividida, a priori, em três grupos principais: área totalmente urbanizada, área em urbanização e área em mata nativa. Todavia, a escala das imagens utilizadas (fotografias aéreas 1:8.000) permite que seja realizada uma classificação mais criteriosa do padrão de cobertura de solo, em especial na mancha urbana, caracterizada por regiões residenciais de diferentes níveis sociais.

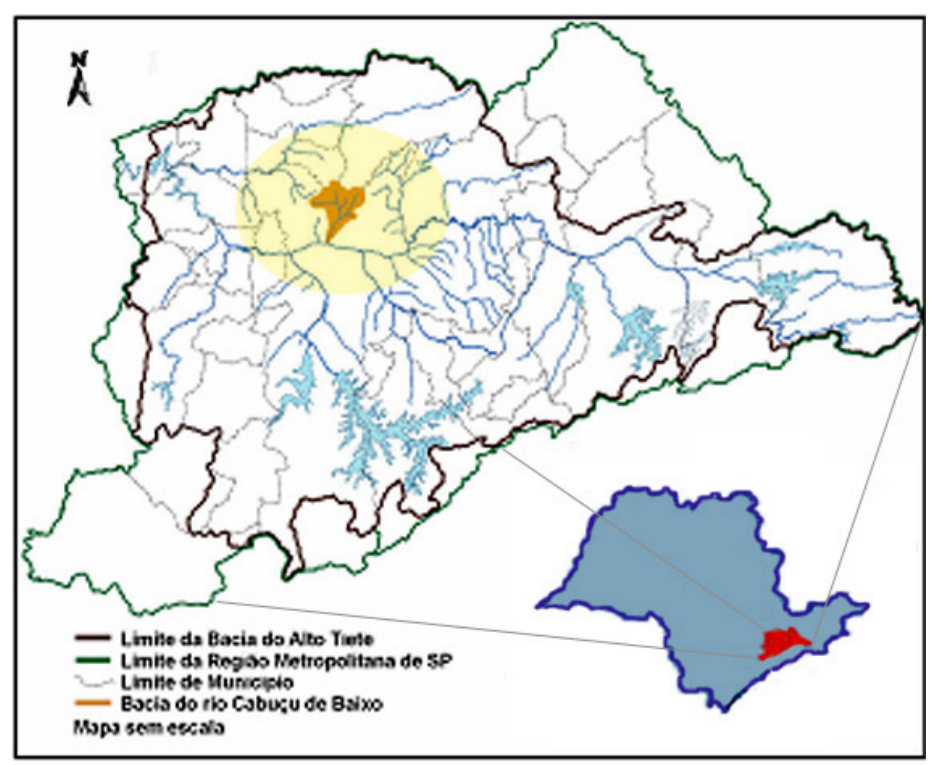

Figura 1. Ilustração sem escala da localização da área do projeto. Destaque para a Região Metropolitana de São Paulo no detalhe menor e para a Bacia do Córrego do Cabuçu no detalhe maior.

Desconsiderando os fatores sociais e econômicos envolvidos, a heterogeneidade da mancha urbana na bacia pode ser notada pelas diferenças no padrão das edificações (aglomeração, dimensão e forma), no sistema viário (pavimentação, largura e traçado) e na redução da arborização. Somados à complexidade do relevo nas áreas de periferia, o padrão de cobertura do solo interfere diretamente na modelagem digital do terreno por estereoscopia, podendo mascarar a superfície real do terreno (Figura 2). 


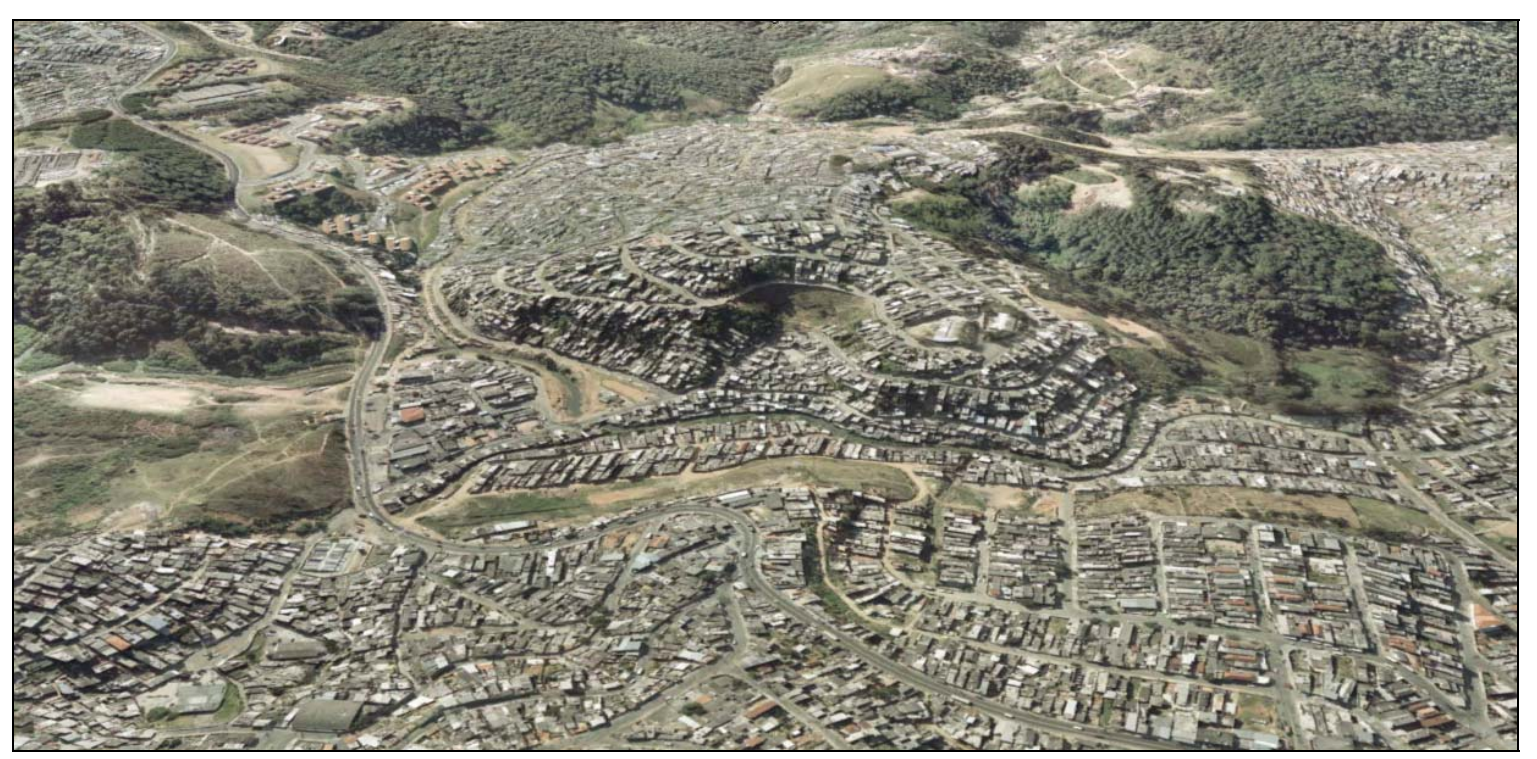

Figura 2. Vista panorâmica ilustrando a complexa heterogeneidade da ocupação do solo em um trecho da bacia.

\subsection{A Escolha do Método}

Neste projeto, a escolha dentre os diferentes métodos para aquisição do MDT levou em consideração fatores como o custo, o tempo e a qualidade. Visando solucionar tal problema, optou-se em utilizar uma solução híbrida, baseada no processo de restituição fotogramétrica digital, recorrendo a processos manuais e automáticos para a criação e modelagem do relevo, remotamente, em ambiente virtual tridimensional.

No entanto, a escolha do método envolveu também a análise da forma com que as informações do terreno seriam representadas. O modo interativo com que o MDT seria constituído, bem como a facilidade de adaptação do TIN às feições do terreno foram fatores limitantes na escolha do modelo adotado.

\subsection{Recursos Utilizados}

Para o desenvolvimento do projeto foi utilizado um conjunto de 68 fotografias áreas (escala 1:8000), fazendo o recobrimento estereoscópico de toda a extensão territorial da bacia, as quais foram obtidas em setembro de 2003. A sobreposição longitudinal média das fotografias é de $60 \%$ e a lateral (sobreposição entre faixas de vôo adjacentes) é de 40\%, estabelecidas previamente no planejamento do vôo. Embora o termo fotografia seja mencionado com freqüência, vale ressaltar que elas foram adquiridas em meio analógico (filme aéreo) e, posteriormente, digitalizadas por meio de um scanner fotogramétrico. As imagens digitais foram padronizadas em RGB 24 bit com 900 dpi, gerando arquivos da ordem de $210 \mathrm{MB}$ por imagem.

Foram levantados 29 pontos de controle em campo, os quais foram definidos previamente em uma etapa de planejamento, avaliando estratégias de distribuição e de freqüência em função da precisão requerida para as medidas tridimensionais ao longo do conjunto de imagens. Para o levantamento, utilizaram-se receptores GPS de padrão geodésico (portadora L1). Foram adotadas feições já existentes no terreno e presentes nas fotografias, como sinalização de trânsito, calçada e muro como referência para as medidas. A alta resolução espacial dessas imagens e a pequena diferença de tempo entre as datas do vôo e do levantamento em campo facilitaram o processo de identificação dessas feições em campo sem que houvesse o comprometimento da qualidade. 
Todos os processamentos foram realizados em um microcomputador padrão PC com processador de $1 \mathrm{GHz}, 2 \mathrm{~GB}$ de RAM e HD de 110 GB. Para auxílio na visualização e medição tridimensional, foi utilizado um estereoscópio (Screenscope) instalado junto ao monitor, dispensando o emprego de recursos gráficos mais sofisticados.

As etapas de aerotriangulação, modelagem digital do terreno, ortorretificação e mosaicagem foram desenvolvidas no sistema Socet Set ${ }^{\circledR}$ V.4.31 da LH System, gentilmente cedido pela Wild Comercial Importadora Ltda. para este trabalho.

\subsection{Preparação das Imagens}

Para o projeto do SSD do Cabuçu de Baixo, inicialmente foi proposto o emprego de um MDT extraído a partir de cartas topográficas do GEGRAN (Grupo Executivo da Grande São Paulo), datadas da década de 70, obtidas por restituição fotogramétrica, bem como imagens do satélite IKONOS II de outubro de 2002, como apoio visual. Em condições normais de ocupação e uso do solo, essa diferença entre as datas não deveria comprometer o estudo, porém a Bacia do Cabuçu de Baixo é tomada por constantes processos de urbanização, acarretando em constantes movimentações do terreno (cortes, aterros, retificação e canalização de córregos).

Visando reduzir o risco de haver eventuais incompatibilidades entre o MDT e a real situação de terreno, a metodologia adotada neste trabalho remeteu ao emprego da aerofotogrametria, utilizando imagens aéreas mais recentes. O fluxograma (Figura 3) ilustra a seqüência das etapas envolvidas.

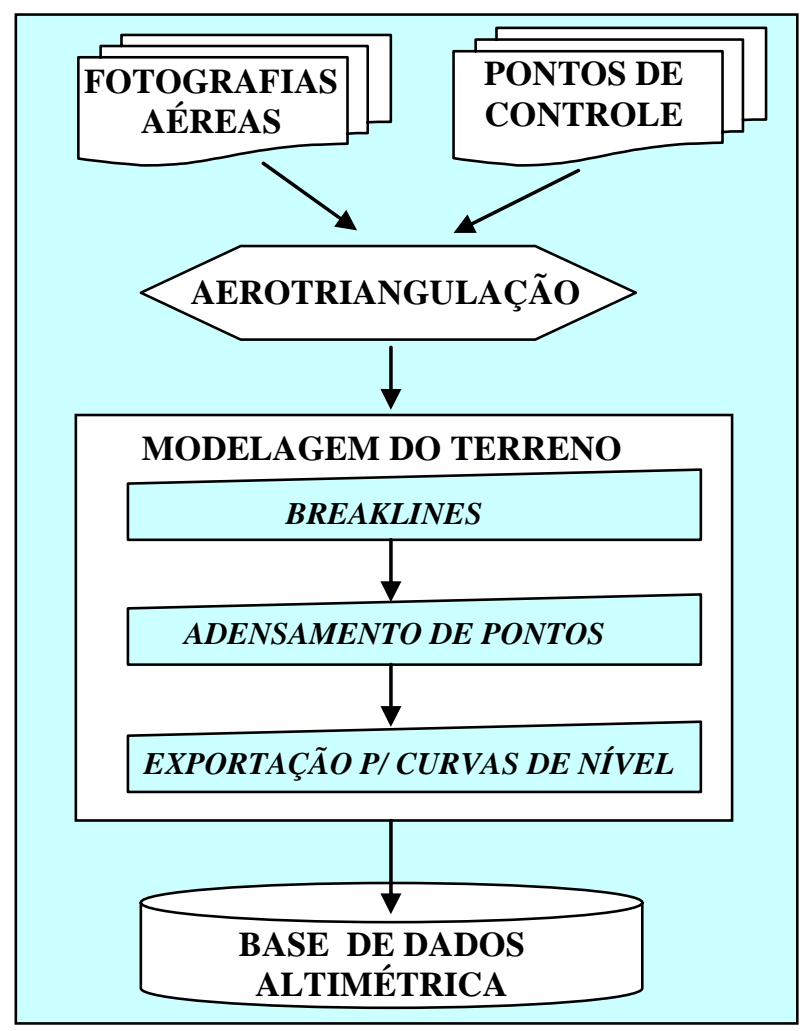

Figura 3. Fluxograma das etapas envolvidas na modelagem digital do terreno.

A preparação das fotografias aéreas para visualização dos modelos estereoscópicos exigiu um processo denominado aerotriangulação, o qual envolveu a amarração das imagens (orientação relativa), utilizando pontos de ligação e, posteriormente, a amarração desse conjunto de imagens aos pontos de controle levantados em campo (orientação absoluta). Ao 
final da aerotriangulação foi possível inferir a acurácia obtida para a medição das feições das imagens em 3D. Uma abordagem detalhada sobre o processo de aerotriangulação pode ser encontrada em McGlone (2004).

Foram utilizados cerca de 1147 pontos de enlace e 29 pontos de controle. Baseado na qualidade da leitura desses pontos, bem como na sua distribuição geométrica, o erro quadrático médio (EQM) final da aerotriangulação foi de $0,44 \mathrm{~m}, 0,48 \mathrm{~m}$ e $0,28 \mathrm{~m}$, respectivamente para os eixos Este, Norte e Elevação. A precisão alcançada mostrou-se compatível à precisão requerida para o modelo de altimetria proposto no trabalho.

\subsection{Modelagem Digital do Terreno}

Uma vez aerotrianguladas as imagens, foi possível iniciar a modelagem digital do terreno utilizando, por sua vez, recursos gráficos que permitem a visualização tridimensional do terreno e das feições nele presentes. Inicialmente, foram restituídas as principais feições que interferem na forma do relevo. Os vetores criados em primeira instância correspondem às linhas de quebra do terreno, denominados como breaklines. Embora fundamentais para o MDT, as breaklines apenas permitem reproduzir a forma aproximada do relevo.

Todavia, os recursos disponíveis no aplicativo utilizado permitiram a visualização simultânea das feições restituídas e das curvas de nível interpoladas em tempo real (Figura 4). Essa visualização facilitou a localização de regiões com densidade insuficiente de breaklines ou regiões cujo MDT não fosse suficientemente representativo.

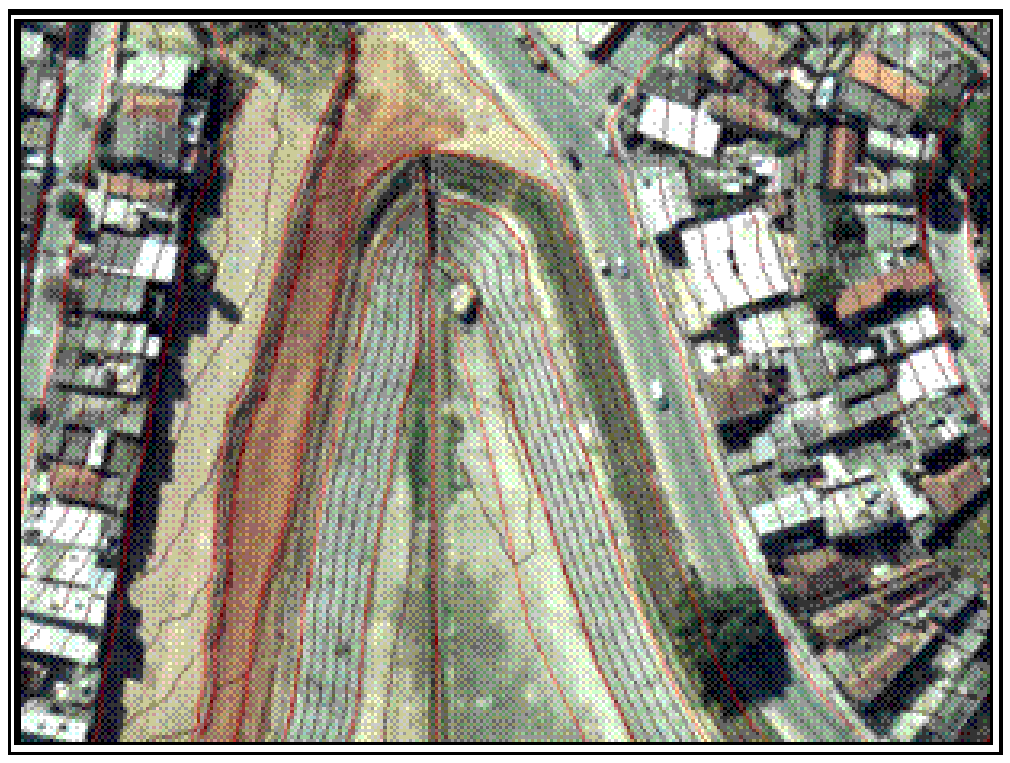

Figura 4. Visualização das breaklines (linhas em vermelho) utilizadas para criar e refinar o MDT em sobreposição a uma ortofoto e as curvas de nível com intervalo de 1 metro no "piscinão" do Guaraú.

Em uma segunda etapa, a modelagem do terreno foi desenvolvida por meio de um adensamento maior de pontos. Em geral, as regiões com pouca variação do terreno, ou com declividades constantes, necessitaram de um número menor de pontos de adensamento. Ao contrário, regiões de relevo mais acidentado foram as maiores candidatas a receber esses pontos. De forma análoga à restituição das breaklines, os pontos foram adicionados manualmente como vértices dos triângulos (Figura 5), pela visualização estereoscópica das imagens. Nesse momento, foram sobrepostas as breaklines, as curvas de nível interpoladas e a malha TIN. 
NÓBREGA, R. A. A.; BARROS, M. T. L. DE; QUINTANILHA, J. A. Emprego de técnicas digitais para a concepção da base cartográfica da bacia hidrográfica do Córrego Cabuçu de Baixo, São Paulo, SP. Ambi-Agua, Taubaté, v. 3, n. 1, p. 76-90, 2008. (doi:10.4136/ambi-agua.44)

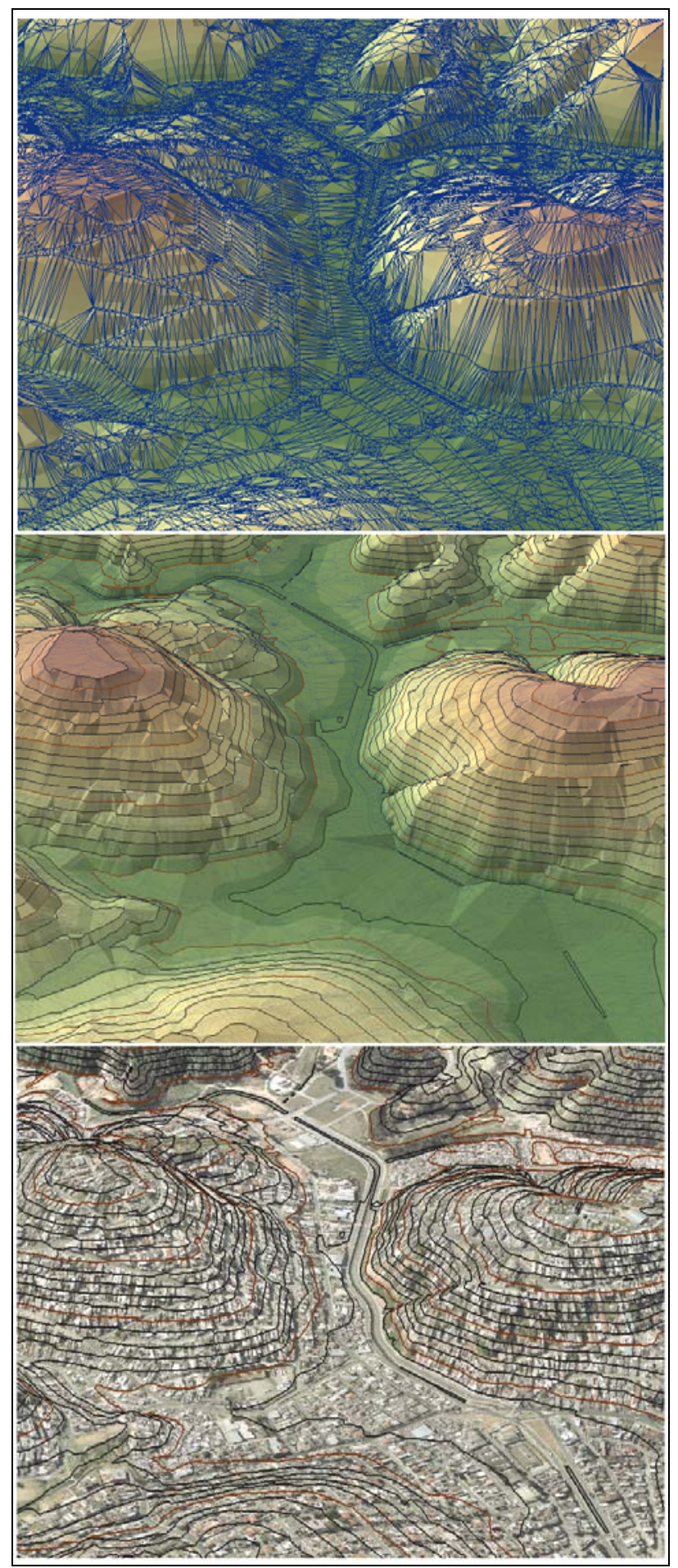

Figura 5. Etapas utilizadas na construção do MDT. Acima: MDT representado por TIN; ao centro: MDT suavizado e sobreposto à altimetria; abaixo: sobreposição com ortofoto em perspectiva.

A interpolação das curvas de nível, nesse caso, apenas forneceu um apoio visual ao operador. Para tanto, reduziu-se gradualmente o intervalo entre as curvas até atingir 1 metro, a fim de representar de forma fiel as feições naturais e artificiais do relevo. A cada ponto adicionado, as curvas foram recalculadas e, em tempo real, mostradas sobre o modelo 
estereoscópico. Assim, interativamente, o MDT foi constituído, apoiado sempre na análise visual do operador, até que toda a extensão da bacia fosse coberta (Figura 6).

Finalizada a construção do MDT, foi necessária sua exportação para que pudesse ser carregado no SSD. Nessa etapa, a opção foi gerar um arquivo vetorial contendo curvas de nível em formato DXF. Esse processo foi realizado em duas etapas, primeiramente um arquivo contendo toda a extenção da bacia com curvas de nível espaçadas a cada 5 metros. Em seguida, um segundo arquivo foi gerado, contendo curvas de nível espaçadas a cada metro, limitadas às proximidades dos rios e suas várzeas, as quais deverão ser adotadas posteriormente para estudos mais detalhados das regiões de alagamento.

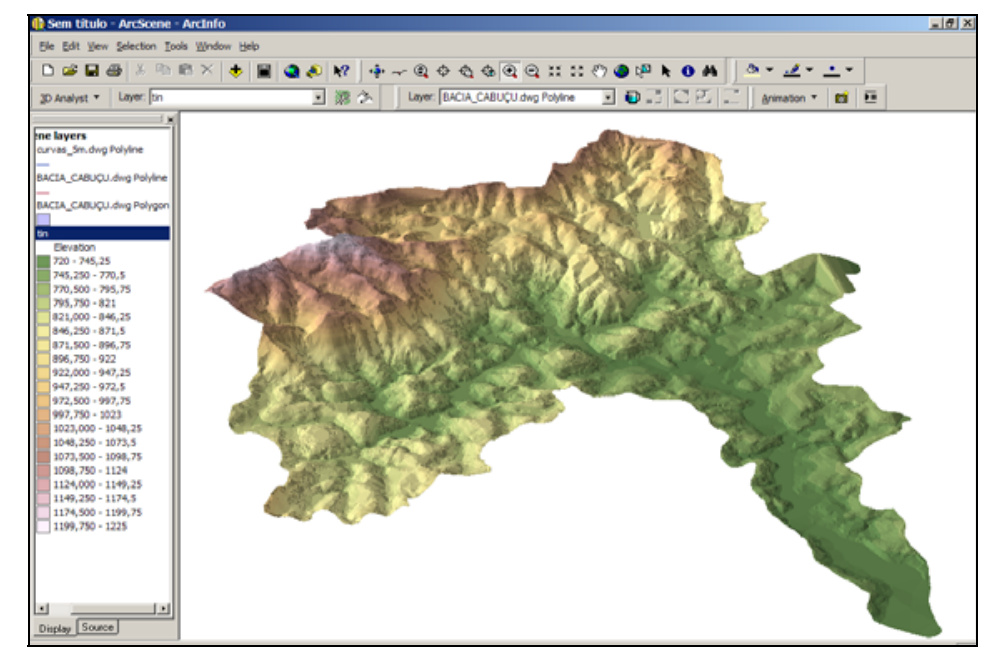

Figura 6. Ilustração do MDT completo da bacia com exagero vertical duplicado no Esri ArcScene ${ }^{\circledR}$.

\subsection{Ortorretificação e Mosaicagem}

A introdução de ortofotos visou subsidiar a carência de informações cartográficas para emprego no SSD. O emprego das ortofotos traz como uma das principais vantagens a total compatibilidade entre as feições presentes nas imagens e a superfície topográfica, uma vez que ambos têm como origem as mesmas fotografias aéreas.

O processo de ortorretificação baseou-se na correção, não uniforme, de distorções geométricas das fotografias, a fim de homogeneizar as diferenças existentes em escala, causadas pela projeção cônica delas e pela variação do relevo. Em tese, modelar o efeito causado pela projeção cônica das fotografias implica conhecimento dos parâmetros que definem a geometria da imagem, como distância focal, altura de vôo e características internas do sensor. As diferenças em escala das imagens causadas pelas irregularidades do terreno são corrigidas a partir do MDT.

Ainda, antes do processamento das ortofotos, as fotografias aéreas sofreram um processo de balanceamento radiométrico, responsável pela homogeneização das tonalidades, do brilho e do contraste delas (Nóbrega, 2002; Nóbrega e Quintanilha, 2004), a fim de minimizar eventuais discrepâncias que podem ser facilmente realçadas nos mosaicos.

Dessa forma, de posse de todos os parâmetros necessários e das imagens balanceadas, foram criadas as ortofotos, priorizando as regiões centrais de cada fotografia. Critérios de verificação da qualidade foram adotados após o processamento de cada ortofoto, como a verificação de regiões excessivamente distorcidas, a ligação entre ortofotos adjacentes e a sobreposição com dados vetoriais, como breaklines e curvas de nível.

O passo seguinte foi a mosaicagem das ortofotos, visando à obtenção de uma imagem única, conservando as propriedades geométricas das ortofotos originais. Nesse processo, 
foram adotadas linhas de corte, inseridas manualmente nas regiões de sobreposição entre duas ortofotos adjacentes. Foram eleitas as feições referentes ao nível do solo, a fim de evitar os efeitos de distorção pela diferença de projeção.

Uma vez mosaicadas, as ortofotos deram origem a um arquivo digital de aproximadamente 1,5 GB, incompatível com a grande maioria dos microcomputadores e aos aplicativos atuais. Nesse caso, a solução foi adotar uma articulação de folhas para recortar o mosaico em imagens menores. O planejamento da articulação levou em consideração a minimização do número de imagens, a facilidade operacional e a capacidade de processamento dos recursos computacionais já existentes no projeto do SSD. Assim, foram geradas 26 imagens (Figura 7) em formato GeoTiff de 228 MB cada, identificadas seqüencialmente por códigos alfanuméricos pré-determinados.

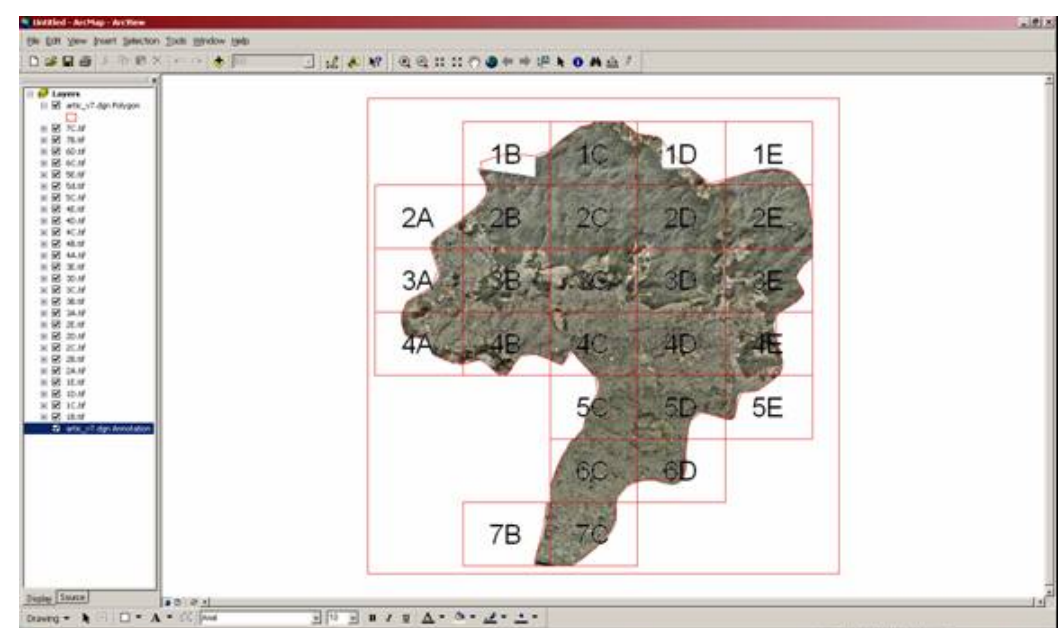

Figura 7. Visualização das imagens finais e da articulação no Esri Arcview $^{\circledR}$.

\section{RESULTADOS E DISCUSSÃO}

Como produto final, foi gerado um MDT de toda a extensão da bacia hidrográfica do Cabuçu. Para emprego no SSDURB, o MDT foi convertido em curvas de nível, disponibilizado em formato vetorial, de acordo com as características requeridas pelo sistema.

A proposta visou também à concepção de ortofotos digitais, as quais foram compiladas a partir das fotografias aéreas utilizadas e do MDT criado. A alta resolução das fotografias aéreas, a precisão geométrica da aerotriangulação, o balanceamento radiométrico e a fidelidade com que as feições do terreno foram representadas no MDT possibilitaram que as ortofotos fossem geradas com uma resolução espacial de $0,2 \mathrm{~m}$ e as feições representadas de modo contínuo, sem quebras.

A análise da precisão do MDT foi realizada comparando-se as altitudes pontos de controle levantados em campo pelos receptores GPS padrão geodésico e as correspondentes altitudes fornecidas pelo MDT. Essa análise foi desenvolvida pelo aplicativo Socet Set e foram considerados apenas os pontos internos à área coberta pelo MDT. Alguns pontos, por estarem localizados nas bordas do MDT, apresentaram resíduos elevados e foram desconsiderados na análise. A análise final mostrou que a média das diferenças foi de 0,5303m com um desvio padrão de 0,8025 e EQM de 0,9377 m. A maior diferença detectada entre os 14 pontos foi de 1,2633 m, o que nos leva a afirmar que, apesar do baixo grau de aderência entre o MDT e a superfície topográfica da bacia, esses resultados foram suficientes 
NÓBREGA, R. A. A.; BARROS, M. T. L. DE; QUINTANILHA, J. A. Emprego de técnicas digitais para a concepção da base cartográfica da bacia hidrográfica do Córrego Cabuçu de Baixo, São Paulo, SP. Ambi-Agua, Taubaté, v. 3, n. 1, p. 76-90, 2008. (doi:10.4136/ambi-agua.44)

para seu uso na aplicação desenvolvida. A Tabela 1 mostra os resultados da análise para os 14 pontos internos á área de interesse.

Tabela 1: Comparação entre altitudes dos pontos de controle e aquelas obtidas via MDT.

\begin{tabular}{c|c|c}
\hline $\mathbf{N}^{\mathbf{0}}$ de pontos & $\begin{array}{c}\text { Identificador do } \\
\text { Ponto }\end{array}$ & $\begin{array}{c}\text { Diferença em altitude } \\
\mathbf{( Z )} \\
(\mathbf{m})\end{array}$ \\
\hline 1 & $\mathrm{P} 06$ & 1,2633 \\
2 & $\mathrm{P} 07$ & 0,1324 \\
3 & $\mathrm{P} 01$ & 1,6637 \\
4 & $\mathrm{P} 04$ & $-0,2138$ \\
5 & $\mathrm{P} 08$ & 0,1258 \\
6 & $\mathrm{P} 09$ & $-1,0345$ \\
7 & $\mathrm{P} 10$ & 1,3090 \\
8 & $\mathrm{P} 11$ & 0,8185 \\
9 & $\mathrm{P} 12$ & 0,5592 \\
10 & $\mathrm{P} 13$ & 0,5449 \\
11 & $\mathrm{P} 14$ & 1,0289 \\
12 & $\mathrm{P} 17$ & $-0,8114$ \\
13 & $\mathrm{P} 18$ & 0,9544 \\
14 & $\mathrm{P} 21$ & 1,0845 \\
\hline
\end{tabular}

A sobreposição das informações altimétricas produzidas com o MDT e das ortofotos afirma a qualidade desses produtos como suporte para as análises visuais e automáticas, se comparados a outras fontes de informação, como a sobreposição entre as curvas de nível da base cartográfica do GEGRAN de 1977 e uma imagem do satélite IKONOS II de 2002 (Figura 8).

Por fim, um mosaico geral foi produzido, permitindo a visualização contínua de toda a extensão da bacia hidrográfica pela junção das 26 ortofotos existentes.
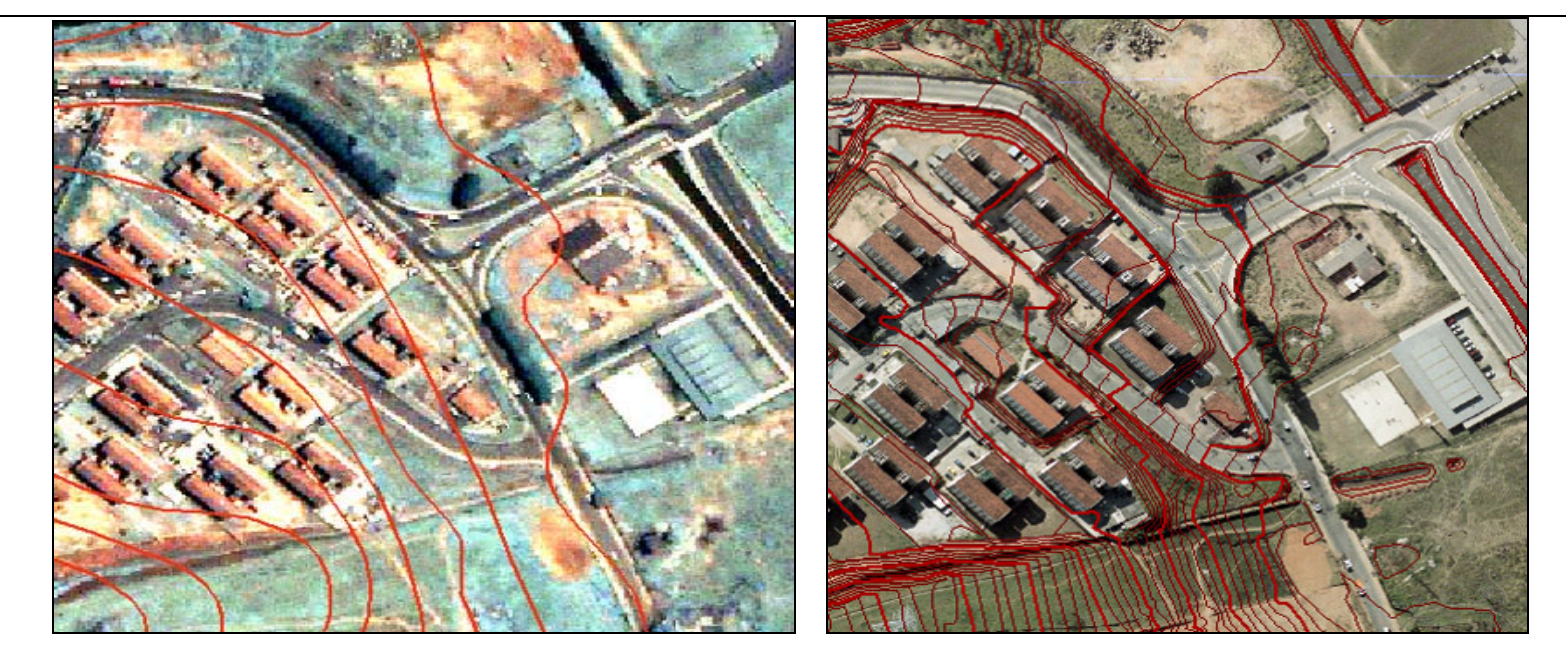

Figura 8. Acima: Curvas de nível GEGRAN 5m (1978) sobrepostas à imagem IKONOS II (outubro de 2002). Abaixo: Curvas de nível $1 \mathrm{~m}$ sobrepostas à ortofoto, ressaltando a movimentação do terreno com o empreendimento construído.

\section{CONCLUSÃO}

O artigo apresenta uma metodologia alternativa desenvolvida para a geração da superfície topográfica e o seu emprego na produção de ortofotos para subsidiar a coleta de 
informações planimétricas, em qualidade compatível com a modelação matemática do SSDURB.

Dadas às restrições de recursos e de tempo, a técnica de mapeamento aqui apresentada demonstrou ser muito adequada às análises feitas pelo SSDURB. A base cartográfica gerada, constituída por cartas altimétricas e ortofotos digitais, possibilitou que o projeto fosse subsidiado por informações precisas, tendo em vista os objetivos do SSD. Além disso, a altimetria permitiu a elaboração de pranchas tridimensionais que em muito contribuíram para análise espacial de propostas de intervenção na bacia, executadas posteriormente (Barros, 2005).

A utilização de um mesmo MDT para geração das ortofotos proporcionou um bom relacionamento entre as feições do terreno, ilustradas na imagem, e representadas pelas curvas de nível. Tais informações são de extrema importância ao SSD, pois permitem, por exemplo, revelar detalhes existentes em áreas sujeitas à inundação.

As vantagens que a adoção de um MDT obtido a partir de uma base cartográfica precisa e atualizada trouxeram ao SSD, foram bastante significativas do ponto de vista operacional. Do ponto de vista econômico, sabe-se que a introdução de um projeto de fotogrametria agrega valores (financeiros) elevados, o que muitas vezes inviabiliza o empreendimento. No entanto, a metodologia proposta nesse trabalho procurou trilhar uma forma diferenciada para suprir as necessidades do SSD. O modelo proposto preservou a precisão nos detalhes semelhante à de uma restituição fotogramétrica manual, e utilizou recursos automáticos disponíveis no aplicativo, em busca da redução no tempo de execução e, conseqüentemente, no custo.

\section{AGRADECIMENTOS}

Os autores agradecem à Escola Politécnica da Universidade de São Paulo, ao CNPq (Conselho Nacional de Desenvolvimento Cientifico e Tecnológico), à Wild Comercial Importadora Ltda. e aos membros da equipe envolvidos no Projeto Gerenciamento Integrado de Bacias Hidrográficas em Áreas Urbanas, Projeto CIAMB 02, 01/97, 03/01-2 PADCT III e aos revisores da revista Ambi-Água pelas sugestões e contribuições.

\section{REFERÊNCIAS}

BARROS, M. T. L. Gerenciamento Integrado de Bacias Hidrográficas em Áreas Urbanas. CNPq, EPUSP. 2004a. Disponível em: <http://www.phd.poli.usp.br/cabucu>. Acesso em: 19 março 2008

BARROS, M. T. L. Gerenciamento Integrado de Bacias Hidrográficas em Áreas Urbanas. São Paulo: CNPq, EPUSP, 2004b. Vol. 1. 52 p.

BARROS, M. T. L. Plano de Bacia Urbana - Relatório Final. São Paulo: EPUSP, FUSP, FINEP, CNPq, 2005.

BURROUGH, P.; MCDONNELL, R. Principles of Geographic Information Systems. New York: Oxford University Press, 1998. 333 p.

CHANDLER, J. Effective application of automated digital photogrammetry for geomorphological research. Earth Surface Processes and Landforms, v. 24, p. 51-63, 1999.

CHOI, J.-Y.; ENGEL, B. A.; THELLER, L.; HARBOR, J. Utilizing web-based gis and sdss for hydrological land use change impact assessment. Transactions of the American Society of Agricultural Engineers, v. 48, n. 2, p. 815-822, 2005. 
DYMOND, R. L.; REGMI, B.; LOHANI, V. K.; DIETZ, R. Interdisciplinary Web-Enabled Spatial Decision Support System for Watershed Management. Journal of Water Resource, Planning, and Management, v. 130, n. 4, p. 290-300, 2004.

DUNN, M.; HICKEY, R. The effect of slope algorithms on slope estimates within a GIS, Cartography, v. 27, p. 9-15, 1998.

GOOCH, M. J.; CHANDLER, J. H. Optimization of strategy parameters used in automated digital elevation model generation. In: DONOGHUE, D. N. M. (Ed.). International archives of photogrammetry and remote sensing. ISPRS, Data Integration: Systems and Techniques, Cambridge, v. 32, n. 2, p. 88- 95, 1998.

JACOBSEN, K. New developments in digital elevation modeling. Geoinformatics, v. 4, n. 5, p. 18-21, 2001.

LOHANI, V.; KIBLER, D. F.; CHANAT, J. Constructing a problem solving environment tool for hydrologic assessment of land use change. Journal of American Water Resources Association, v. 38, n. 2, p. 439-452, 2002.

MCGLONE, C. (Ed.) Manual of photogrammetry. 5.ed. Bethesda: American Society for Photogrammetry and Remote Sensing, 2004. 1151p.

MAUNE, D. F. Digital elevation model technologies and applications: the DEM user manual. 2.ed. Bethesda: American Society for Photogrammetry and Remote Sensing, 2007. 655 p.

NÓBREGA, R. A. A. Análise do balanceamento de imagens aplicado a fotogrametria. 2002. 119p. Dissertação (Mestrado em Engenharia de Transportes - Área de Informações Espaciais/Geoprocessamento) - Escola Politécnica da Universidade de São Paulo, São Paulo. 2002.

NÓBREGA, R. A. A., QUINTANILHA, J. A. Comparative analysis of automatic digital image balancing and standard histogram enhancement techniques in remote sensing images. Revista Brasileira de Cartografia. Curitiba - PR: , v.56, n.1, p.55 - 64. 2004.

QUEIROZ FILHO, A. P. Ortofoto digital para atualização cartográfica em um sistema de informações geográficas. 1993. 132 p. Dissertação (Mestrado em Engenharia de Transportes - Área de Informações Espaciais/Geoprocessamento) - Escola Politécnica da Universidade de São Paulo, São Paulo, 1993.

RAINIS, R. Estimating sediment yield using Agricultural Non-Point Sources (AGNPS) model: the effects of slope information from different GIS software. Journal of Spatial Hydrology, v. 4, n. 2, 2004.

SKIDMORE, A. A. Comparison of techniques for calculating gradient and aspect from a gridded digital elevation model. International Journal of Geographical Information Science, v. 3, p. 323-334, 1989.

TAYLER, K.; WALKER, G.; ABEL, D. A framework for model integration in spatial decision support systems. International Journal of Geographical Information Science, v. 13, n. 6, p. 533- 555, 1999. 
XU, Z. X.; ITO, K.; SCHULTZ, G. A.; LI, J. Y. Integrated hydrologic modeling and GIS in water resources management. Journal of Computing in Civil Engineering, v. 15, n. 3, p. 217-223, 2001.

WATSON, L. T.; LOHANI, V. K.; KIBLER, D. F.; DYNOND, R. L.; N.RAMAKRISHNAN, N.; SHAFFER, C. F. Integrated computing environments for watershed management. Journal of Computing in Civil Engineering, v. 16, n. 4, p. 259-268, 2002.

WECHSLER, S. P. Uncertainties associated with digital elevation models for hydrological applications: a review. Hydrology and Earth System Sciences, v. 11, p. 1481-1500, 2007.

WILSON, J. P.; MITASOVA H.; WRIGHT, D. J. Water resource applications of geographic information systems. URISA Journal, v. 12, n.2, p. 61-79, 2000.

ZEILHOFER, P. Modelação do relevo e obtenção de parâmetros fisiográficos na Bacia do Rio Cuiabá. Revista Brasileira de Recursos Hídricos, v. 6, n. 3, p. 95-109, 2001.

ZERGER, A.; WEALANDS, S. Beyond Modelling: Linking Models with GIS for Flood Risk Management. Natural Hazards, v. 33, p.191-208, 2004.

ZHOU, G.; CHEN, W.; KELMELIS, J. A.; ZHANG, D. A Comprehensive Study on Urban True Orthorectification. IEEE Transactions on Geoscinecce and Remote Sensing, v. 43, n. 9, p. 2138-2147, 2005. 